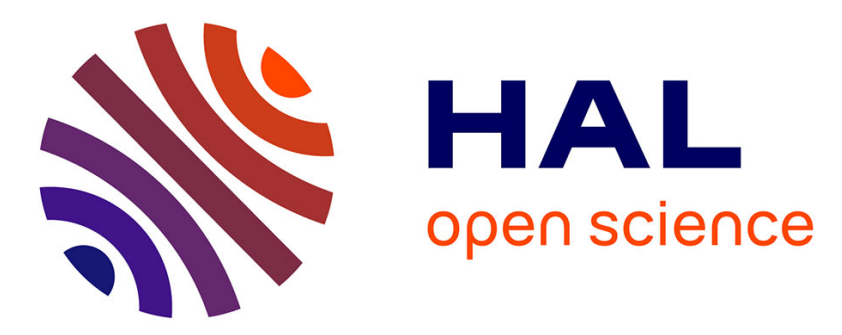

\title{
Sensitivity of mineral dust concentrations to the model size distribution accuracy
}

Laurent Menut, Gilles Foret, Gilles Bergametti

\section{To cite this version:}

Laurent Menut, Gilles Foret, Gilles Bergametti. Sensitivity of mineral dust concentrations to the model size distribution accuracy. Journal of Geophysical Research: Atmospheres, 2007, 112 (D10), pp.D10210. 10.1029/2006JD007766 . hal-02326028

\section{HAL Id: hal-02326028 \\ https://hal.science/hal-02326028}

Submitted on 22 Oct 2019

HAL is a multi-disciplinary open access archive for the deposit and dissemination of scientific research documents, whether they are published or not. The documents may come from teaching and research institutions in France or abroad, or from public or private research centers.
L'archive ouverte pluridisciplinaire HAL, est destinée au dépôt et à la diffusion de documents scientifiques de niveau recherche, publiés ou non, émanant des établissements d'enseignement et de recherche français ou étrangers, des laboratoires publics ou privés. 


\title{
Sensitivity of mineral dust concentrations to the model size distribution accuracy
}

\author{
Laurent Menut, ${ }^{1}$ Gilles Forêt, ${ }^{2}$ and Gilles Bergametti ${ }^{2}$ \\ Received 7 July 2006; revised 3 January 2007; accepted 15 February 2007; published 22 May 2007.
}

[1] Evaluating the impacts of atmospheric dust on marine ecosystems and climate requires the use of three-dimensional transport models including a size-resolved bins scheme to describe the evolution of the particle size distribution. Recently, Forêt et al. (2006) proposed an alternative size bins scheme to better account for the physical size-dependent processes such as dry deposition. This paper evaluates the benefit of using this new bin scheme in three-dimensional transport models. This is achieved by performing a one-and-a-half month simulation with the CHIMERE-DUST model forced by the Mesoscale Model, Version 5 (MM5)/National Center for Environmental Prediction (NCEP) analysis fields, for an area covering the northern Atlantic Sea and the western Africa. Compared to a reference run performed using a large number of size bins (40), our results show that the size bins scheme proposed by Forêt et al. (2006) reduces at least by a factor of 2 the numerical errors on the simulated concentrations compared to the classical isolog bins scheme for the same number of size bins. However, with this new bins scheme requiring to define the bins according to a dry deposition velocity corresponding to a given friction velocity, we examine the errors associated to this constraint.

Citation: Menut, L., G. Forêt, and G. Bergametti (2007), Sensitivity of mineral dust concentrations to the model size distribution accuracy, J. Geophys. Res., 112, D10210, doi:10.1029/2006JD007766.

\section{Introduction}

[2] Dust emitted from arid and semiarid areas of the Earth strongly affect the biogeochemical cycles [e.g., Jickells et al., 2005] and the Earth radiative budget [e.g., Sokolik et al., 2001]. The assessment of these impacts either at regional or global scale requires to perform three-dimensional simulations to retrieve dust concentrations and deposition. Many processes to account for in these dust models are size dependent. Since the dust size distribution covers more than 2 orders of magnitude in diameter, most of the transport models use a particle size-resolved bins scheme. This corresponds to the discretization of the particle size distribution into a finite number of size classes (bins). This discretization is unchanged all along the simulation, from the dust emission (the source) to the terminal deposition (the sink). Since each size bin has to be transported independently, the computing time is directly dependent on the number of size bins used in the model. Thus most of the models try to limit the number of transported particle size bins in order to reduce the computing time. However, the greater the number of bins is, the less the resulting concentrations will be affected by numerical inaccuracies. Thus a

\footnotetext{
${ }^{1}$ Laboratoire de Météorologie Dynamique, Institut Pierre-Simon Laplace, Ecole Polytechnique, Palaiseau, France.

${ }^{2}$ Laboratoire Inter-Universitaire des Systèmes Atmosphériques, Universités Paris7-Paris 12-CNRS, Créteil, France.

Copyright 2007 by the American Geophysical Union. 0148-0227/07/2006JD007766\$09.00
}

compromise has to be made, and the selected particle size bins scheme mainly depends on the computing capabilities and on the objectives of the simulation. In the literature, the number of size bins used in dust transport models ranges from 1 [Alpert et al., 2004; Kishcha et al., 2005] to 12 [Uno et al., 2003; Han et al., 2004], roughly ranging from 0.1 to $10 \mu \mathrm{m}$ in diameter. Within this interval, four particle size bins, covering generally the size range $0.1-20 \mu \mathrm{m}$ in diameter, are the most frequently used [Luo et al., 2002; Cakmur et al., 2004; Ginoux et al., 2004; Grini and Zender, 2004]. In all cases, models use isolog bins to represent the dust size distribution, i.e., a scheme in which the size domain covered by each bin is equal in $\log \left(\Delta D_{\mathrm{p}}\right)$.

[3] Several sensitivity studies were previously performed to optimize the number of bins, according to the previous constraints. For example, Schulz et al. [1998] noted that 20 isolog bins are sufficient to reduce numerical errors. Gong et al. [2003] concluded that a minimum of 12 isolog size bins are necessary to simulate correctly the mass and number size distributions of dust. Previous studies were devoted to the best way to represent bins-based size distributions. Among them, and more directed toward aerosols nucleation and coagulation studies, the works of Sandu et al. [2005] and von Salzen [2006] proposed interesting methods to limit numerical errors when aerosol mass moves from one bin to another one. In this paper, we considered that the exchange between size bins are limited for primary particles like dust, and thus the bins are independently transported (i.e., no dealing interbins exchanges). 




Figure 1. Map of the CHIMERE-DUST simulation domain. The "Atlantic" domain (ATL) used in this study extended as $-90^{\circ} \mathrm{W}<\lambda<+90^{\circ} \mathrm{E}$ and $-10^{\circ} \mathrm{S}<\phi<+60^{\circ} \mathrm{N}$. The domain where the potential dust emissions are diagnosed is quoted "EMISSIONS".

[4] Recently Forêt et al. [2006] proposed an alternative approach consisting in defining the size bins according to the gradient of the dry deposition velocity, with respect to the particle diameter, instead of the classical isolog size bins. In their study, a simple zero-dimensional model was used to quantify the errors induced by using various size bins scheme. They inferred a large initial dust size distribution (from 0.01 to $63 \mu \mathrm{m}$ ) and examined the difference observed on the simulated dust concentrations between a reference simulation (using 1000 size bins) and the different size bins schemes after 48 or 144 hours of transport. The results showed that, for a similar number of bins, the errors are significantly reduced when using the isogradient size bins scheme. They also showed that using less than 10 isolog size bins leads to errors greater than $10 \%$ on the dust concentrations.

[5] In order to check the capability of the scheme of Forêt et al. [2006] to better reproduce dust concentrations fields, we implement it in the three-dimensional transport model CHIMERE-DUST. The use of this scheme into a threedimensional model may lead to different results than those obtained with the zero-dimensional model used by Forêt et al. [2006] for idealized configurations, mainly because of the natural spatial and temporal variability of the surface features (roughness, topography, and the induced complex surface layer dynamics). Thus it is interesting to investigate how this bins scheme works when implemented in a threedimensional model.

[6] In this study, several simulations covering one month and a half over February and March 2004 are performed by using both the isograd and isolog bins schemes and for different numbers of particle size bins. The accuracy of the simulated dust concentration fields will be evaluated by comparing the simulations conducted with each particle size bins scheme to a simulation performed with a sufficiently large number of bins (40 size bins) to be considered as a reference. In section 2, the transport model as well as the test cases are presented. The studied case is introduced in section 3. The results for the simulated concentrations are discussed in section 4, and the impact of each bins scheme on the simulated concentrations is discussed in section 5 . Finally, conclusions are presented in section 6 .

\section{Dust Modeling}

\subsection{The CHIMERE-DUST Model}

\subsubsection{The Meteorological Forcing}

[7] CHIMERE-DUST is a transport model dedicated to mineral dust only. It was developed on the basis of the chemistry-transport model CHIMERE [Vautard et al., 2001; Bessagnet et al., 2004] currently used for boundary layer regional air pollution studies and forecast. Since CHIMERE-DUST is an off-line model, meteorological fields are required: For this study, the National Center for Environmental Prediction (NCEP)/Global Forecast System (GFS) meteorological fields are used to force the regional Mesoscale Model, Version 5 (MM5 [Dudhia, 1993]). The outputs of MM5 have a horizontal resolution of $1^{\circ} \times 1^{\circ}$, with 32 vertical levels, from surface to $200 \mathrm{hPa}$. The horizontal domain, "ATL" frame in Figure 1, covers the whole North Atlantic Ocean, including a large part of the northern Africa and of the western Europe. The results of the MM5 simulations (the wind components, the temperature, the specific humidity, the pressure fields, the $2 \mathrm{~m}$ temperature, and the sensible and latent surface heat fluxes) are used to diagnose additional turbulent parameters such as the boundary layer height $\bar{h}$, the friction velocity $u_{*}$ using a bulk Richardson profile approach as described by Menut [2003], and the water liquid content (for the wet deposition). From all these parameters, vertically averaged meteorological profiles are estimated for the CHIMERE-DUST configuration, switching from 32 to 15 vertical levels.

\subsubsection{The Transport Model CHIMERE-DUST}

[8] The CHIMERE-DUST is driven by MM5 meteorological fields at an hourly time step and over the same horizontal domain, with $1^{\circ} \times 1^{\circ}$ resolution. Boundary conditions for the dust are not taken into account, considering the domain sufficiently large to include all the major dust sources. The dust concentration is initialized to zero at 
the first time step, but we consider a long spin-up time in order to study realistic dust concentrations: In this study, the model ran 15 days before the first date of interest. The horizontal transport is computed using the scheme of Van Leer [1979]. The dust simulations are performed with a $7^{\prime} 30^{\prime \prime}$ time step, and the dust concentrations are extracted every hour for posttreatment.

[9] The emissions scheme used in the model is first based on the dust production model by Marticorena and Bergametti [1995]. This model is used to compute horizontal fluxes from wind velocities and surface features for the emissions area (the "EMISSIONS" area in Figure 1). Then, the dust vertical fluxes are derived from the horizontal fluxes by using the parameterization by Alfaro and Gomes [2001], numerically optimized following Menut et al. [2005]. The vertical fluxes are computed corresponding to three dust size modes, then redistributed into the model size bins using the following mass partition scheme:

$$
m_{i}=\sum_{n} \frac{m_{n}}{2}\left|\operatorname{erf}\left(\frac{\ln d_{i, 1} / \mathrm{Dp}_{n}}{\sqrt{2} \cdot \ln \sigma_{n}}\right)-\operatorname{erf}\left(\frac{\ln d_{i, \mathrm{u}} / \mathrm{Dp} \mathrm{p}_{n}}{\sqrt{2} \cdot \ln \sigma_{n}}\right)\right|
$$

where $m_{i}$ and $m_{n}$ are the emitted masses in the model bins and in the three emitted modes, respectively. $\mathrm{Dp}_{n}$ and $\sigma_{n}$ are the emitted mass diameters and associated standard deviations (as described by Menut et al. [2005]), and $d_{i, 1}$ and $d_{i, \mathrm{u}}$ are the diameter of the lower and upper limits of each dust size bin, respectively.

[10] The wet deposition scheme is that described in the work of Loosmore and Cederwall [2004]. The dry deposition velocity is parameterized following Venkatram and Pleim [1999]:

$$
V_{\mathrm{d}}=\frac{v_{\mathrm{s}}}{1-\mathrm{e}^{-\left(r_{\mathrm{a}}+r_{\mathrm{b}}\right) v_{\mathrm{s}}}}
$$

where $r_{\mathrm{a}}$ and $r_{\mathrm{b}}$ are the aerodynamical and laminar resistances and $V_{\mathrm{s}}$ is the settling velocity. These two resistances are estimated as presented in the study by Seinfeld and Pandis [1998]. This parameterization differs slightly from other well-known dry deposition parameterizations but has the advantage to be theoretically more accurate for large particles. For example, the parameterization by Zhang et al. [2001] offers a detailed description of the laminar resistance more adapted to changing surfaces as urbanized areas, forest, or crops. In our case, areas where dust deposition occurs are mainly arid areas or sea. Sensitivity tests performed by Forêt et al. [2006] showed negligible differences for these types of surfaces when different values were taken for $r_{\mathrm{b}}$. We thus kept the one described in the study by Venkatram and Pleim [1999]. The settling velocity is a key parameter: While the various resistances work only in the first vertical layer (i.e., physically, only in the air layer in contact with the surface), the settling velocity is a permanent deposition process acting over the whole atmospheric column in which dust are present. The expression for $V_{\mathrm{s}}$ is:

$$
V_{\mathrm{s}}=\frac{1}{18} \frac{D_{\mathrm{p}}^{2} \rho_{\mathrm{p}} g C_{\mathrm{c}}}{\mu_{\text {air }}}
$$

with $C_{\mathrm{c}}$ a "slip correction factor" (calculated using the relationships described by Seinfeld and Pandis [1998]), $D_{\mathrm{p}}$ is the particle diameter (in $\mu \mathrm{m}$ ), $\rho_{\mathrm{p}}$ is the particle density (in our case, chosen constant and equal to $\rho_{\mathrm{p}}=2.65 \mathrm{~g} \mathrm{~cm}^{-3}$ ), $\mu_{\text {air }}=1.72 \times 10^{-4} \mathrm{~g} \mathrm{~cm}^{-1} \mathrm{~s}^{-1}$ is the air kinematic viscosity of the air, and $g$ is the gravity acceleration with $g=981 \mathrm{~cm} \mathrm{~s}^{-1}$.

\subsection{Simulations Design}

[11] Five simulations, differing either by the number of particle size bins or by the method used to define these size bins, were performed. The size distribution was equal for each simulation and ranged from 0.01 to $63 \mu \mathrm{m}$. This interval was selected in order to cover all processes potentially acting on dust behavior from the source (where large particles are dominant) up to remote areas (where only finer particles remain in the atmosphere). The reference case Ref40 corresponds to a simulation performed using 40 isolog size bins. We consider, according to previous studies [Gong et al., 2003; Forêt et al., 2006], that such a number of size bins lead to negligible numerical errors in dry deposition computation whatever the bin scheme. Thus this simulation will be considered as an "absolute" reference to which the other simulations can be compared to evaluate only the errors resulting from the discretization of the dust size distribution.

[12] Two simulations, just differing by the number of isolog size bins (6 and 12), have been performed and will be referred in the text as $\log 6$ and $\log 12$, respectively. Two additional simulations are also performed using 6 and 12 size bins defined using the "dry deposition velocity gradient" approach proposed by Forêt et al. [2006]. These simulations will be later called Grad6 and Grad12, respectively. The calculation of the dust size distribution is as follows. We first define a work interval: the distribution ranges from $d_{1}=0.01 \mu \mathrm{m}$ to $d_{2}=63 \mu \mathrm{m}$. Thus we follow four different steps:

[13] - For a given friction velocity, the deposition velocity is estimated as a function of the particle diameter $\left(D_{\mathrm{p}}\right)$, according to equation (2).

[14] - The particle diameter corresponding to the minimum value $\min \left(V_{\mathrm{d}}\right)$ is diagnosed. We thus divide the size range in two domains: the domain I defined by the size interval $\left[d_{1}: d_{\min \left(V_{\mathrm{d}}\right)}\right)$ in which the dry deposition velocity increases when the particle size decreases (mainly because of Brownian diffusion) and the domain II within the size

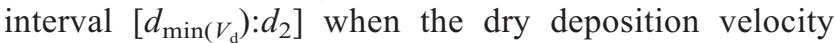
increases with the particle size (in this case, mainly because of gravitation, dependent on square particle diameter, and for particles in the diameter range $4-15 \mu \mathrm{m}$, due to impaction and interception processes at the surface).

[15] - For a given number of bins, $n$, we first calculate $\Delta V_{d}^{\mathrm{II}}=\left(V_{d_{2}}-V_{d_{\text {min }}}\right) /(n-1)$ and $\Delta V_{d}^{\mathrm{I}}=\left(V_{d_{\min }}-V_{d_{1}}\right)$. Thus we implicitly consider that domains $I$ and $I I$ have 1 and $n-1$ bins, respectively.

[16] - Then, we use an iterative procedure using the following test: If $\Delta V_{d}^{\mathrm{II}}<\Delta V_{d}^{\mathrm{I}}$, then one bin is transferred from domain $I I$ to domain $I$. When the condition is not reached, it means that the splitting of the size distribution in size bins is well done.

\section{The Selected Period}

[17] The selected period for the simulations ranges from 31 January to 16 March 2004. This period is especially 


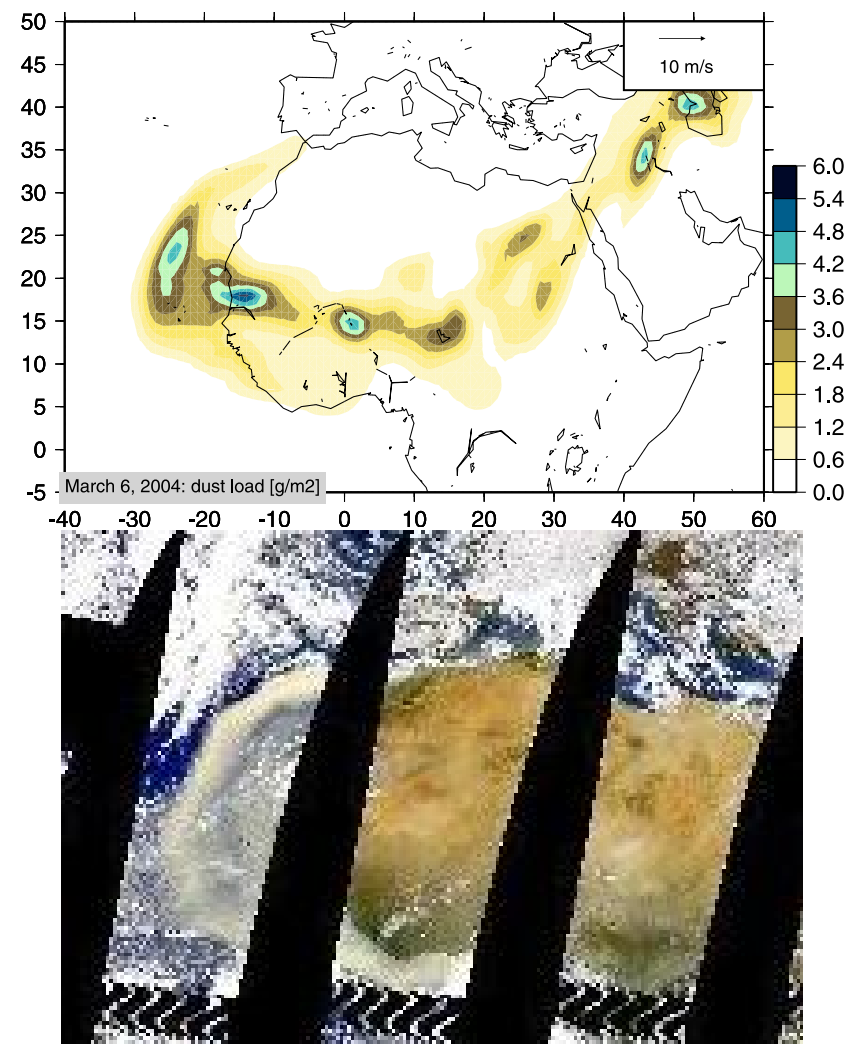

Figure 2. Simulated atmospheric column dust load of mineral dust (in $\mathrm{g} \mathrm{m}^{-2}$ ) for 6 March 2004. The image was recorded by SEAWIFS (http://www.nrlmry.navy.mil/aerosol/ satellite/seawifs/) and corresponds to the same period, clearly showing the dust plume over the sea.

remarkable for the huge dust storm occurring over western Africa on 6 March 2004. This dust event leads to important aerosol optical thickness (AOT) as recorded by the AERONET stations [Holben et al., 2001] where AOT reaches 1.8 at $550 \mathrm{~nm}$ in Sal Island (Capo Verde). As seen on satellite images (Figure 2), this dust plume flew over the African coastline heading toward the south of Spain and finally penetrated into the Mediterranean air basin.

[18] To make comparisons, we extracted simulated dust concentrations at selected sites (see also map in Figure 1) as follows:

[19] $\bullet$ Niamey (longitude $-2.35^{\circ} \mathrm{W}$, latitude $+13.5^{\circ} \mathrm{N}$ and altitude $218 \mathrm{~m}$ a.s.1.) is located in a region close to the area where dust are emitted and is also downwind others important sources.

[20] - Sal Island in Capo Verde (longitude $-22.93^{\circ} \mathrm{W}$, latitude $+16.73^{\circ} \mathrm{N}$ and altitude $60 \mathrm{~m}$ a.s.l.) is located in the Atlantic Ocean, close to the sources and on the way of the major dust plumes emerging from the Sahara or Sahel.

[21] - Izana in Canary Islands (longitude $-16.80^{\circ} \mathrm{W}$, latitude $+28.5^{\circ} \mathrm{N}$, altitude $2367 \mathrm{~m}$ a.s.1.) is also located in the Atlantic Ocean and is frequently on the route of dust emitted from African sources and reaching the Mediterranean sea.

[22] - Barbados Island (longitude $-59.72^{\circ} \mathrm{W}$, latitude $+13.28^{\circ} \mathrm{N}$ and altitude $0 \mathrm{~m}$ a.s.l.) is located in the most western part of the Atlantic Ocean and can be considered as representative for long-range transported dust.
[23] Figure 2 shows that the general pattern of the dust plume is satisfyingly reproduced by the model (using the Ref40 configuration). Figure 3 a reports time series of surface concentrations for Capo Verde. In order to compare the model outputs with the AOT measured by the AERONET network [Holben et al., 2001], we computed modeled AOT using dust concentrations integrated all along the atmospheric column. This comparison (Figure 3b) shows that the model reproduces correctly the magnitude of the observed AOT over the eastern Atlantic.

[24] In this section, we presented a general comparison between measured and modeled AOT. The aim of this section is not to discuss in details about the model accuracy, but to show that the simulations performed with that model are sufficiently realistic to be used to compare the two size bins scheme.

\section{Methodology for an Optimal Friction Velocity Estimation}

\subsection{Methodology}

[25] As indicated in section 2.2, the isograd method needs to prescribe a priori a friction velocity to define the dry deposition velocity function from which the isograd size bins are defined. This choice is mandatory since these size bins remain unchanged during the whole simulation even if the surface features (and thus the roughness length) and the wind speed (and thus $u *$ ) evolve during the transport of the dusty air masses. Forêt et al. [2006] investigated this aspect in their box model and showed that this effect could generate errors up to $20 \%$.

[26] To determine this "optimal" $u *$ value, we examined the distributions of roughness length and of the wind speed over the continent. The distribution of the roughness length in the model $z_{0 \mathrm{~m}}$ is presented in Figure 4 (top). The largest occurrence appears for $z_{0 \mathrm{~m}}=3.5 \mathrm{~cm}\left(z_{0 \mathrm{~m}}=0.5 \mathrm{~cm}\right.$ is here relevant to a uniform value representative of the sea).

[27] For the wind speed, we estimated the distribution of the $10-\mathrm{m}$ wind speed, used for the estimation of the friction velocity. We used all values modeled over the continental domain and over the whole simulated period. The largest

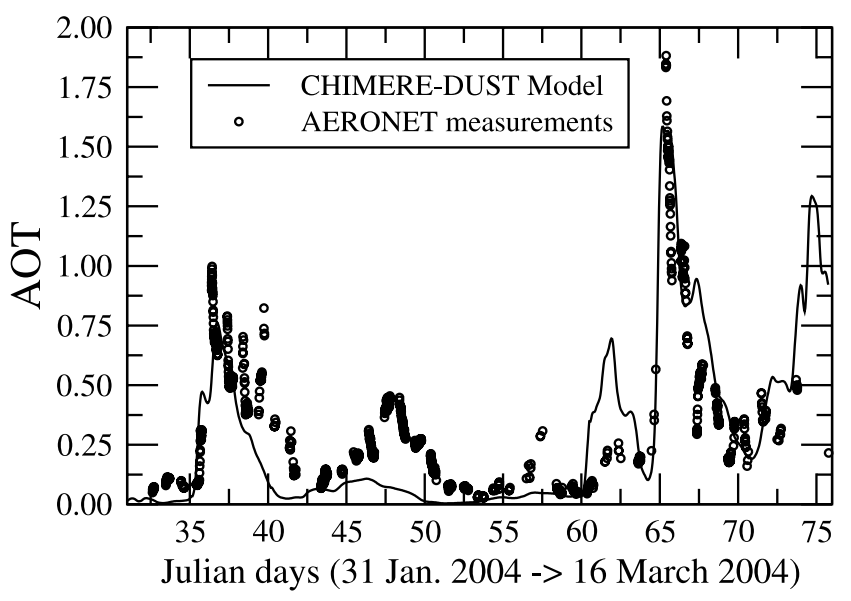

Figure 3. Time series of concentrations and diagnosed aerosol optical thickness over the Capo Verde site. AOT data are issued from the AERONET network [Holben et al., 2001]. The Julian day 65 corresponds to 6 March 2004. 

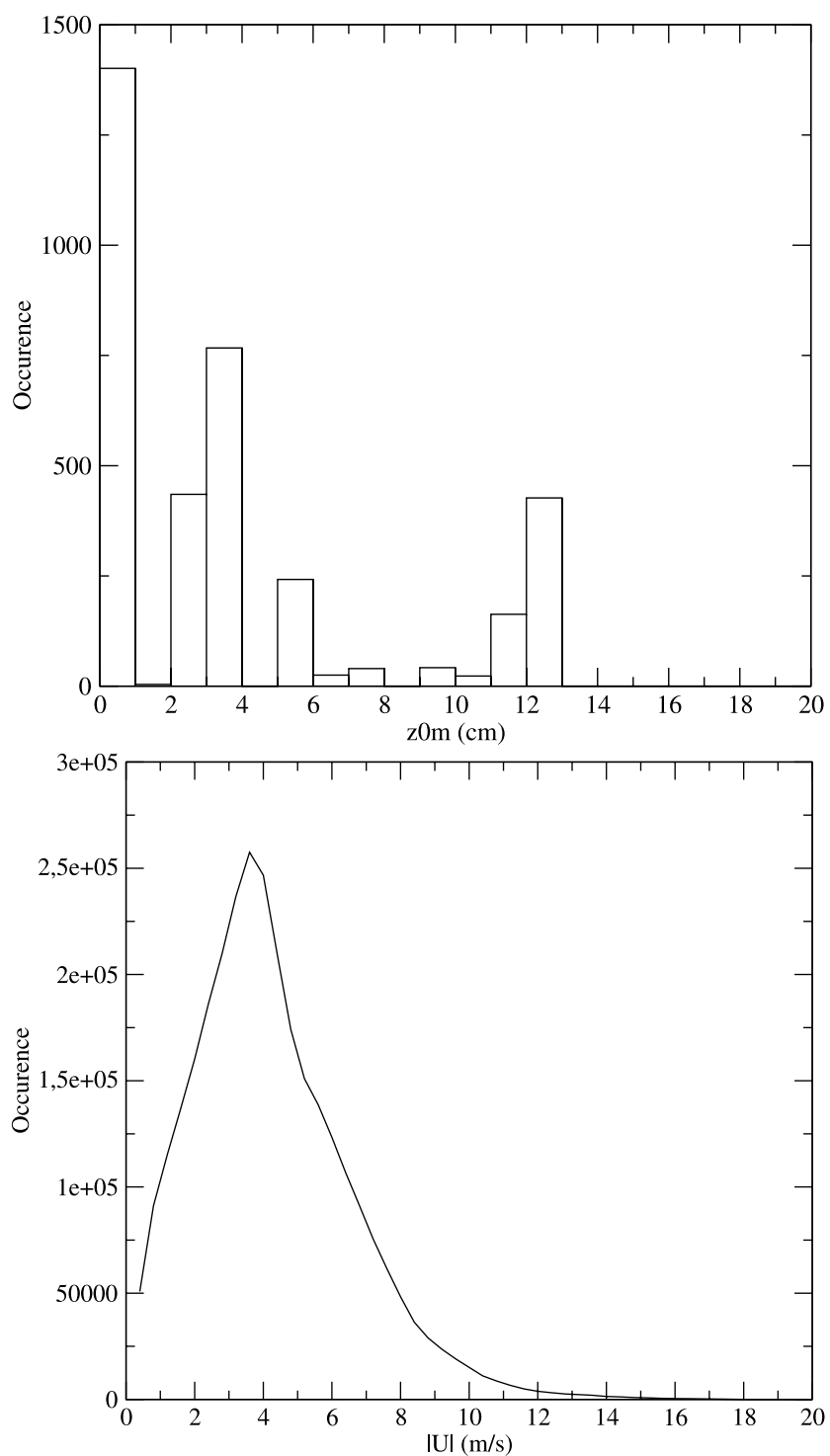

Figure 4. Distribution of roughness length $z_{0 \mathrm{~m}}(\mathrm{~cm})$ over the whole domain (top) and of the $10 \mathrm{~m}$ above ground level wind speed, $|U|$ (m/s; bottom).

occurrence appears for a median value of $|U| \approx 5 \mathrm{~m} / \mathrm{s}$ (Figure 4, bottom). The computation of $u *$ under neutral conditions (but we consider here this hypothesis of the second order compared to the median searched value) is:

$$
u_{*}=|U| \frac{k}{\ln \left(z / z_{0 \mathrm{~m}}\right)}
$$

with $z=10 \mathrm{~m}$, the height above ground level where the wind speed is estimated by the meteorological model. We found in this case $u * \approx 0.3625 \mathrm{~m} / \mathrm{s}$. As a first-guess, we can thus use the value of $u * \approx 0.35 \mathrm{~m} / \mathrm{s}$ for our optimized distribution.

\subsection{Sensitivity to the Fixed Friction Velocity}

[28] The previous methodology leads, as requested, to a reference friction velocity that can be easily used to define the isogradient size bins. However, as observed in Figure 4, the distributions of the roughness length and 10-m wind speed exhibited a large spread around the median value. Thus it is necessary to estimate the uncertainties resulting from the selection of a given value of the friction velocity on the finally modeled concentrations.

[29] We first considered a reference run with 40 bins. Second, we estimated a 12-bin isograd distributions (hereafter called Grad12) using the estimated value of $u *=$ $0.35 \mathrm{~m} / \mathrm{s}$. In order to estimate the variability of the modeled concentrations depending on other possible $u *$ values, we ran the same configuration but with $u *=0.2$ and $0.5 \mathrm{~m} / \mathrm{s}$. The differences in dust concentrations (first model level) are estimated between Ref40 and Grad12 and for each of the $u *$ value for some selected locations.

[30] Results are displayed in Figure 5 for Capo Verde, Izana, and Barbados. Clearly, the simulation performed using $u *=0.5 \mathrm{~m} / \mathrm{s}$ is the worst one. The differences when comparing to Ref40 are the most important with concentrations up to $200 \mu \mathrm{g} \mathrm{m}^{-3}$ in Capo Verde and Izana for some days of March 2004. Obviously, the difference is less marked over Barbados Islands (less than $10 \mu \mathrm{g} \mathrm{m}^{-3}$ ) because of significantly lower concentrations.

[31] Our goal is to determine the mean $u *$ value leading to the smallest variability in the dust concentrations results compared to the reference case. Following this way, the presented methodology suggest that the simulations performed using $u *=0.35 \mathrm{~m} / \mathrm{s}$ lead to the best agreement. Thus we retained this value to define the isogradient size bins. Since this selection was performed over a relatively longtime period, with an hourly time step to catch the whole

Capo Verde: [Ref40-Grad12]
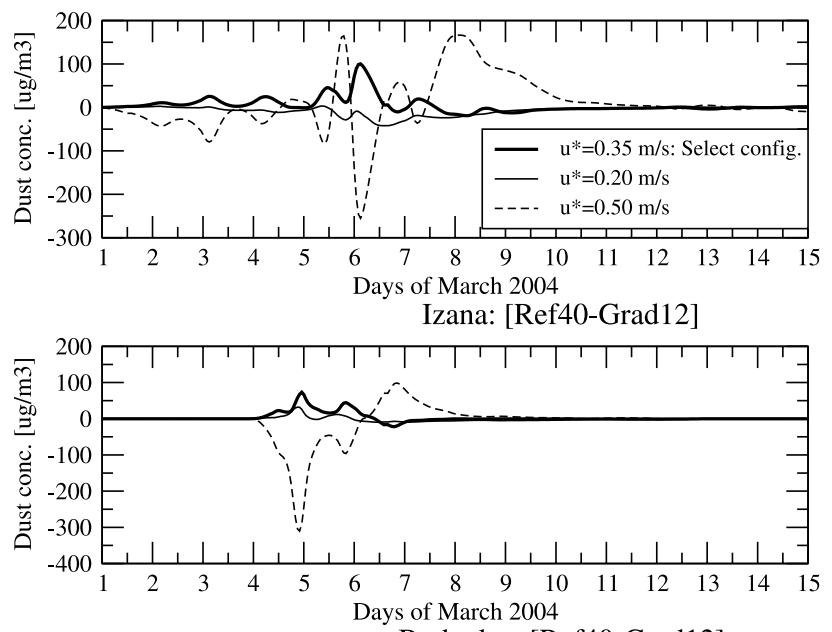

Barbados: [Ref40-Grad12]

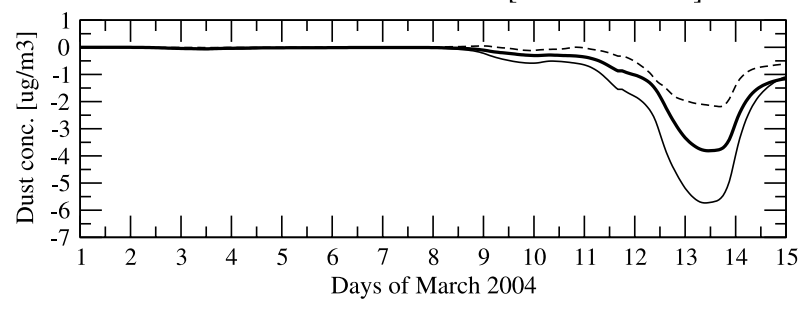

Figure 5. Sensitivity test performed using the gradient size bins scheme. Difference in dust concentrations versus Ref40 are given for gradient size bins computed for $u *=$ $0.2,0.35$, and $0.5 \mathrm{~m} / \mathrm{s}$. 
Capo Verde

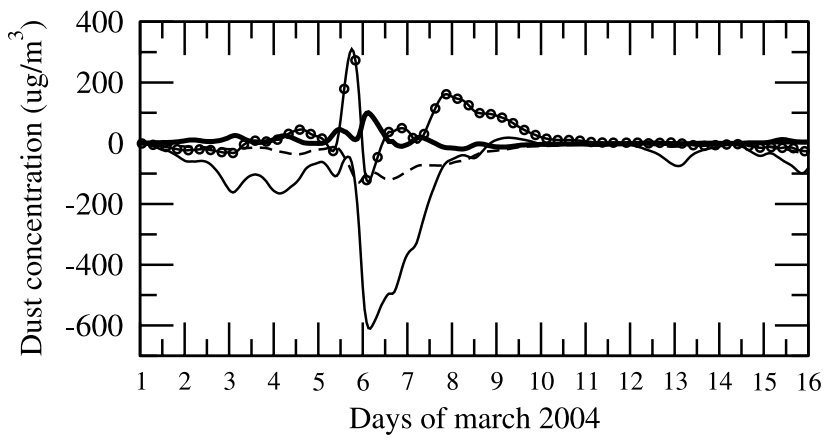

Izana

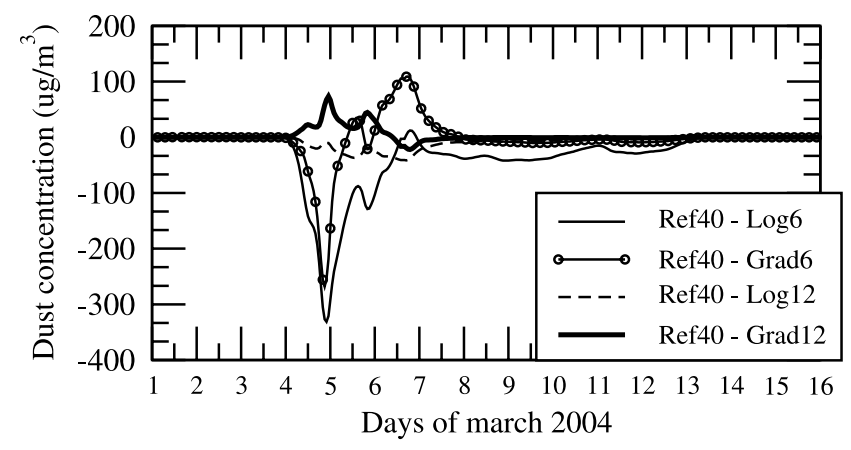

Barbados

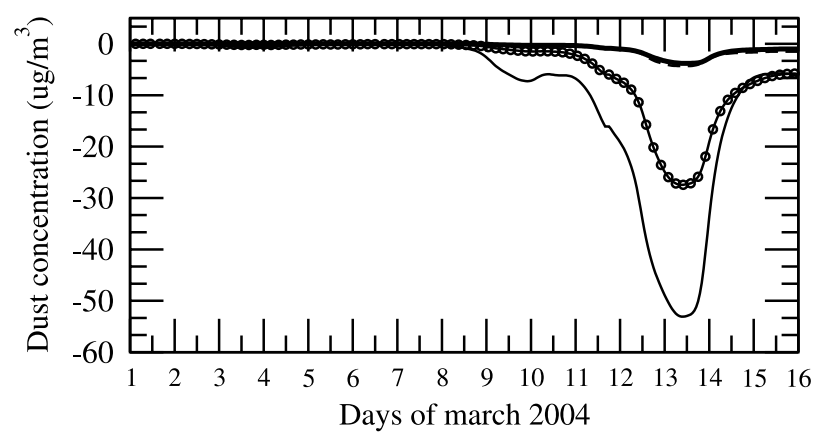

Figure 6. Differences in surface concentrations between the reference run (Ref40) and the different model configurations (Log6, Grad6, Log12, and Grad12) for 116 March 2004. Values are displayed for three sites: Capo Verde, Izana, and Barbados.

diurnal cycle, and over a large domain (including emissions sources, deserts, and sea), we can consider that this result may be used with confidence for other periods and sites.

\section{Results}

[32] In this section, we present comparisons between the dust concentrations fields as simulated using the Ref40 configuration and those simulated with the four other configurations ( $\log 6, \log 12$, Grad6, and Grad12). In the following, the dust concentrations are presented as integrated over all size bins, i.e., providing the total mass in each grid cell and for each hour.

\subsection{Absolute Differences and Ratios}

[33] Figure 6 displays the differences between the two number of size bins for each of two size bins schemes and the Ref40 as a function of the time. The whole simulated period ranges from 1 to 16 March 2004, and results are displayed for restricted periods.

[34] Results are reported for three sites Capo Verde, Izana, and Barbados located, as mentioned above, at different distances from the dust sources. Obviously, because of this difference in locations, the dust plume reaches the different sites on different days. Thus we focus our analysis to the periods when the dust plume reaches each site (which generally correspond to the periods during which the differences are maximum between the different schemes). The largest differences according to Ref40 are systematically observed for the simulations performed with only 6 bins. This is true whatever the size bins scheme used for the simulation. This highlights the direct link existing between the number of bins used in the model and the accuracy of the simulated concentrations in dust transport models. Moreover, the differences between Ref40 and the four other simulations show a large variability around zero (positive and negative values). Clearly, the differences between the size bins schemes are not a systematic bias, and thus it would be difficult to propose a method allowing to correct the simulated concentrations as a function of the number of size bins used in the model. The best results, i.e., the lowest differences according to Ref40, are those obtained with the Grad12 method. Over the three sites, the Grad12 size bins scheme leads to significantly lower errors than $\log 12$ (the same tendency is observed for the simulations performed with 6 size bins for which the gradient method is also more accurate than the isolog one).

[35] The previous results directly depend on the magnitude of the simulated concentrations for each sites. Thus we report for the same three sites, on ratio, the ratios between the concentrations simulated with 12 bins for each size bins scheme and those simulated with Ref40. A complete agreement between a 12-size bins scheme and the Ref40 leads to a ratio of 1 , while an underestimate (overestimate) leads to a ratio lower (greater) than 1 . The period for the simulations is extended from 1 February to 15 March in order to examine the behavior of each scheme not only during high dust period but also during background dust conditions.

[36] Figure 7 shows that all configurations exhibit a large changing ratio as a function of time. Over Capo Verde, $\log 12$ and Grad12 display errors less than $10 \%$ in both cases. While the error oscillates around 1 with Grad12, a small underestimation is found with $\log 12(\approx 0.95)$. The same behavior is observed over Izana, with more or less the same temporal changes and similar differences for the two schemes. The signal is clearest far from the sources after a long-range transport. Indeed, in Barbados, if all configurations underestimate the concentrations compared to the reference case, the Grad12 leads to an accuracy roughly two times better than $\log 12$.

\subsection{Horizontal Maps of Ratios}

[37] We now focus on 6 March 2004 (Figure 8). As mentioned above, this event offers the opportunity to test the two size bins schemes for different dust transport time. The huge dust event occurring over western Africa and its transport along the African coast allow evaluating how each size bins scheme reproduces the dust concentrations fields, from a "young" plume for which the dry deposition is 
Capo Verde

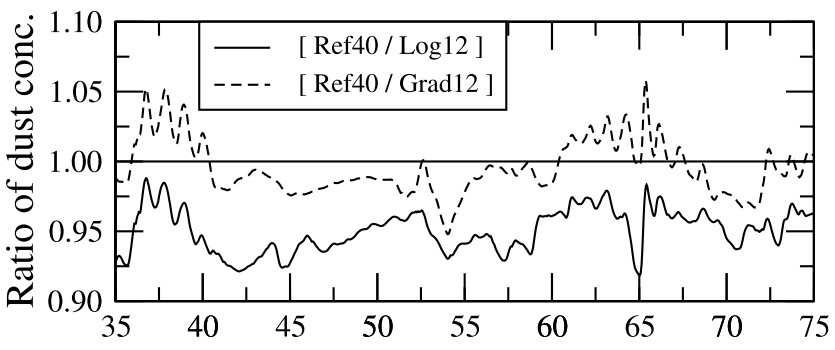

Izana

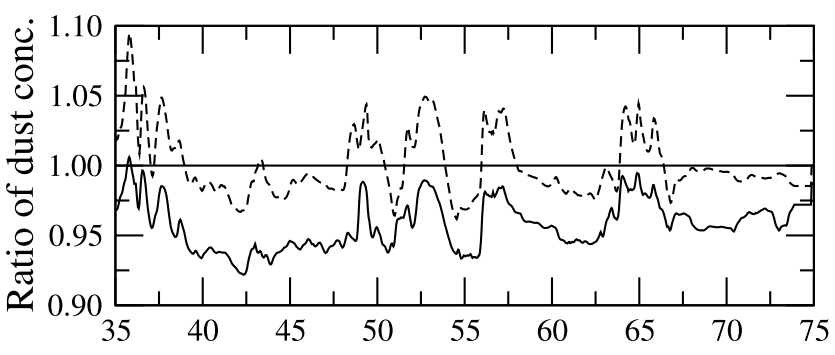

Barbados

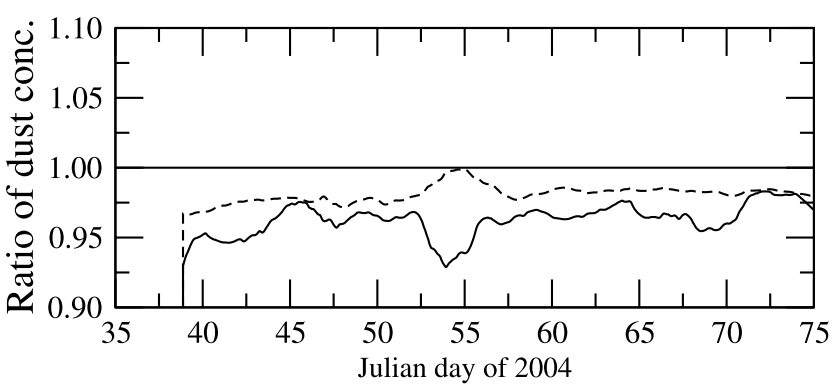

Figure 7. Surface concentrations ratios between the reference run (Ref40) and the two size bins schemes configurations (Log12 and Grad12) for the 2004 Julian days 35-75 (i.e., 4 February to 15 March 2004). Values are displayed for three sites: Capo Verde, Izana, and Barbados.

mainly controlled by the largest particles up to an aged plume in which remains mainly the smallest dust particles. Thus looking at the difference in concentrations (according to Ref40) simulated by using the two size bins schemes will
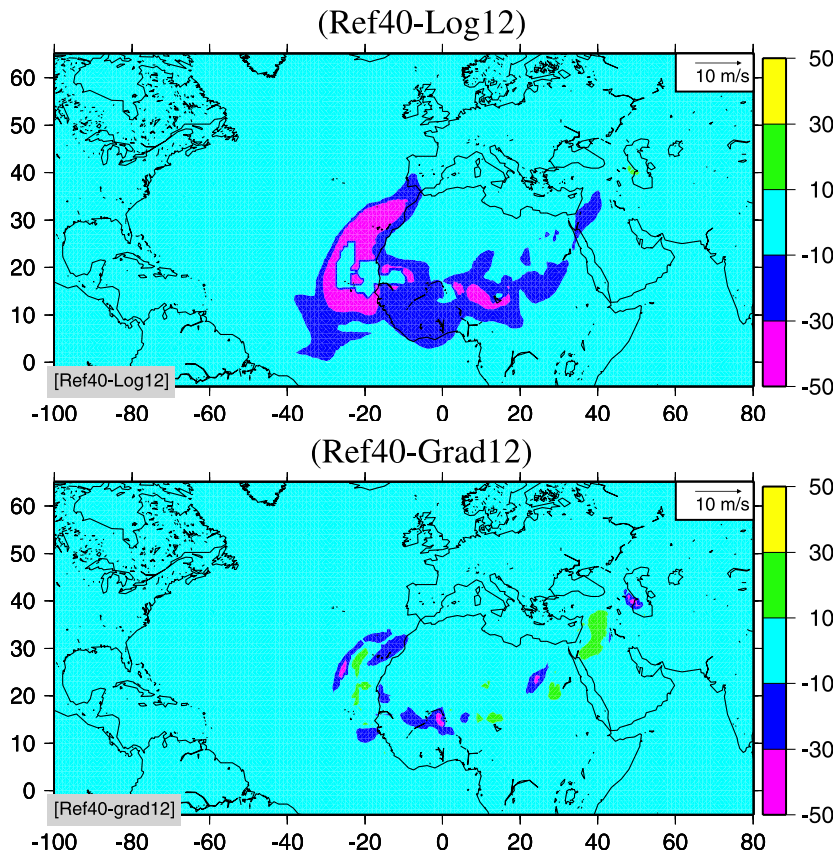

Figure 9. Absolute differences in concentrations $\left(\mu \mathrm{g} \mathrm{m}^{-3}\right)$ between the reference run (Ref40) and the several simplified model configurations. Maps for 6 March 2006, 00:00. Results are presented for each panel with: top, surface concentrations (Ref40-Log12, top); bottom, same but for Ref40-Grad12.

estimate their respective capabilities to correctly reproduce the dust dry deposition for different transport times.

[38] In order to compare the two configurations, we present the differences calculated for a given time but over the whole simulation domain. The plots of Figure 9 compare the 12 size bins configurations. The absolute concentrations values are compared to the reference run (Figure 8).

[39] The results show that the $\log 12$ scheme induces a severe overestimation of the dust mass over the ocean (around $80-100 \mu \mathrm{g} \mathrm{m}^{-3}$ ) and over the western Africa. These errors are significantly reduced by using the Grad12 scheme. With this latter scheme, we only diagnosed a slight underestimation over land, more precisely over the arid emitting regions. Clearly, these results show that using an

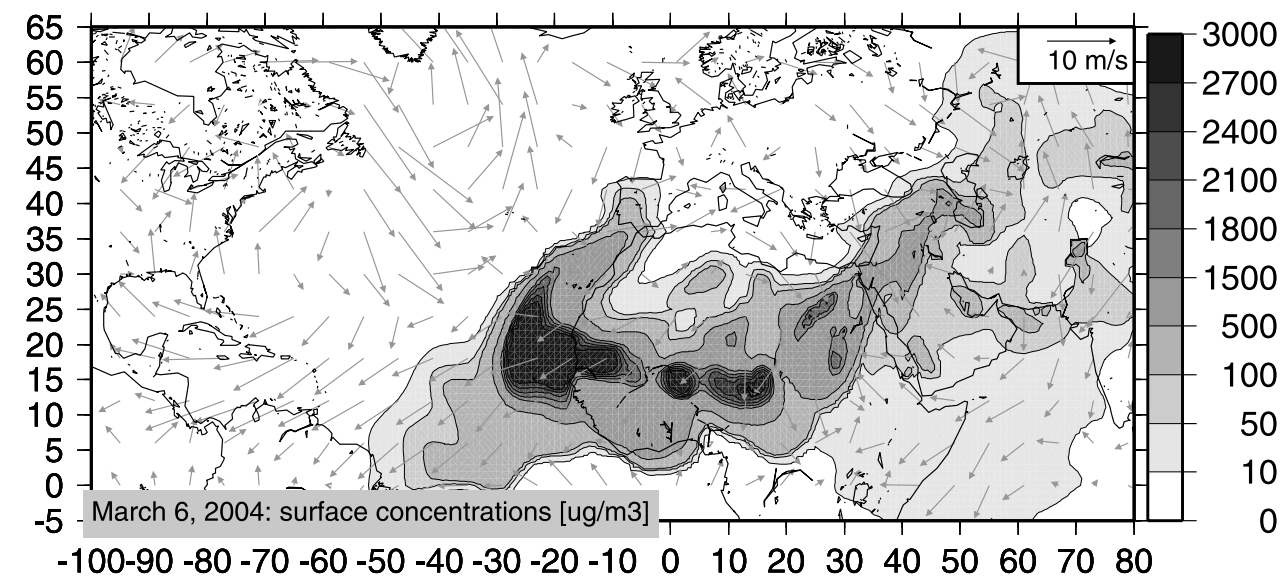

Figure 8. Modeled surface dust concentrations for 6 March 2004 in $\mu \mathrm{g} \mathrm{m}^{-3}$. 
Niamey: March 4, 2004

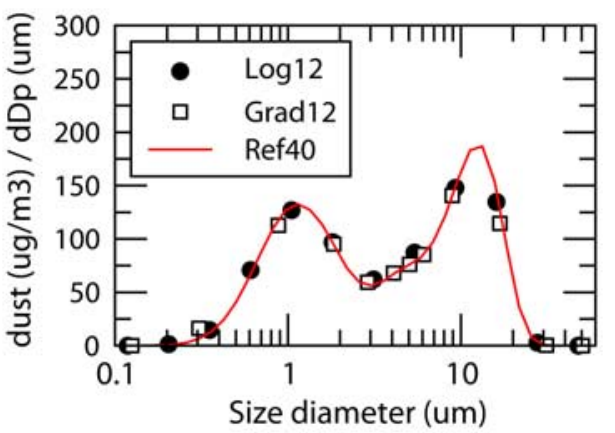

Capo Verde: March 6, 2004

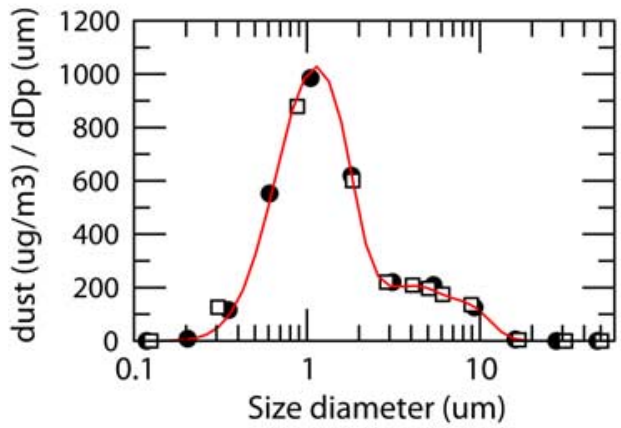

Capo Verde: March 5, 2004


Figure 10. Dust mass concentrations distributions over three locations (Niamey, Capo Verde, and Izana) for 5, 6, and 7 March 2004, respectively. The dust concentrations are normalized by the bin width in order to compare the distributions Ref40, Log12, and Grad12.

isolog size bins scheme, even when using 12 bins, leads to significant errors on the simulated dust concentrations fields. These errors can be significantly corrected by using the Grad12 size bins scheme.

\subsection{Size Distribution}

[40] The previous sections have pointed out that the errors produced by the two size bins schemes are not homogeneously distributed in space and time. In order to better assess the reasons for such differences, we examined the mass size distributions simulated by each size bins scheme.

[41] Figure 10 presents the surface mass size distributions as simulated over Niamey, Capo Verde, and Izana with the two size bins schemes using 12 bins. Different dates have been selected for each site in order to document as close as possible the same air mass, i.e., that containing the dust emitted in the region of Niamey on 4 March. According to the simulations, this air mass is transported over Capo Verde on 5 and 6 March and, finally, passed over Izana on 7 March.

[42] Over Niamey, the mass size distribution is strongly dominated by the coarse mode, i.e., particles between 2 and $15 \mu \mathrm{m}$. The predominance of this large particle size range is an indicator of "fresh" dust, near the dust source area and for which dry deposition processes have not yet significantly acted. When comparing the two size bins schemes, the main difference is related to the size bin around $6 \mu \mathrm{m}$ in diameter. A part of these aerosols is transported over Capo Verde the following day, 5 March. The main size bin contributing to the dust mass remains in the coarse mode, and the differences between the two configurations begin to be significant. The situation changes drastically on 6 March
2004 over Capo Verde and on 7 March 2004 over Izana. For this latter site, the Log12 configuration exhibits a mass size distribution with two modes having similar abundances. Grad12 exhibits a more important contribution of the fine mode (with a diameter less than $1 \mu \mathrm{m}$ ). This is only due to the difference between the two distributions, but, globally, the mass is the same between the two configurations as shown with the next figure. These results exhibit different shapes of the size distributions depending on the sites and on the size bins scheme used. Taking in mind the importance of the dust size distribution for evaluating the deposition to the oceans or the dust radiative impact, these results point out the importance of having an accurate size distribution scheme to correctly simulate the concentrations of mineral dust.

[43] Figure 11 presents the cumulative concentrations for the same period and the same sites than Figure 10 allowing a direct comparison of the evolution of the dust mass simulated when using each of the two size bins scheme. It appears that for particle size diameters less than $\approx 2 \mu \mathrm{m}$ in diameter, the two 12 size bins schemes overestimate the concentrations compared to Ref40. The results differ for the size bins representing diameters up to $\approx 2 \mu \mathrm{m}$. We clearly diagnose that Grad12 is able to stay more accurate, thanks to the bins chosen in the diameter interval $2-10 \mu \mathrm{m}$ : Indeed, the Grad12 size bins scheme has 5 bins over this size range (where the gradient of the deposition velocity is high), while the $\log 12$ has only 3 bins over the same size range.

[44] As expected, the temporal evolution of the simulated mass size distribution corresponds to a continuous decrease 


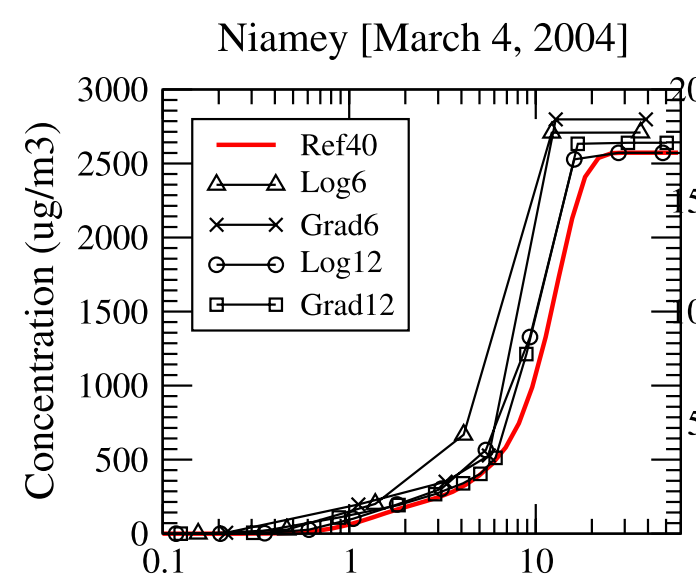

\section{Capo Verde [March 5, 2004]}
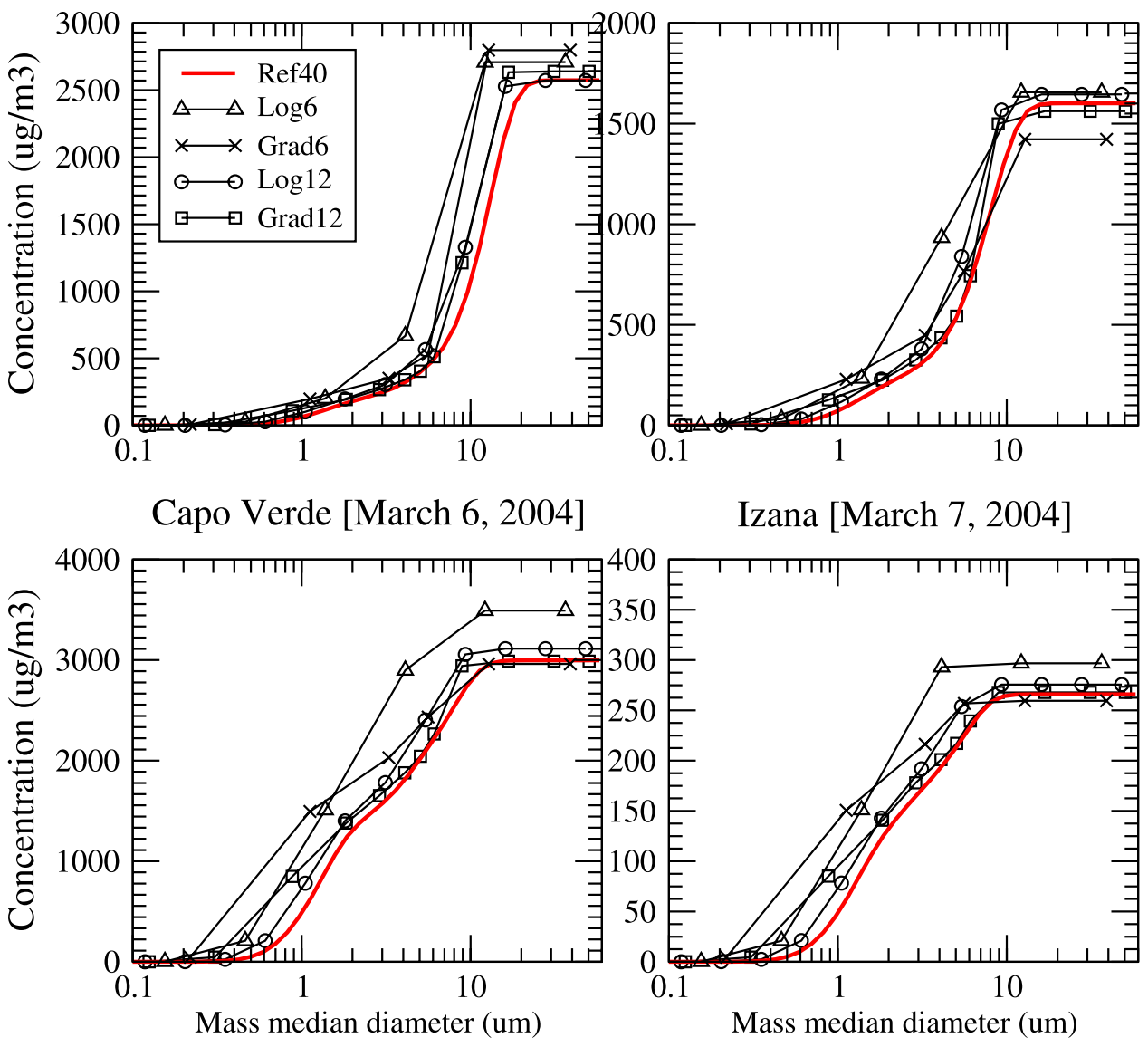

Izana [March 7, 2004]

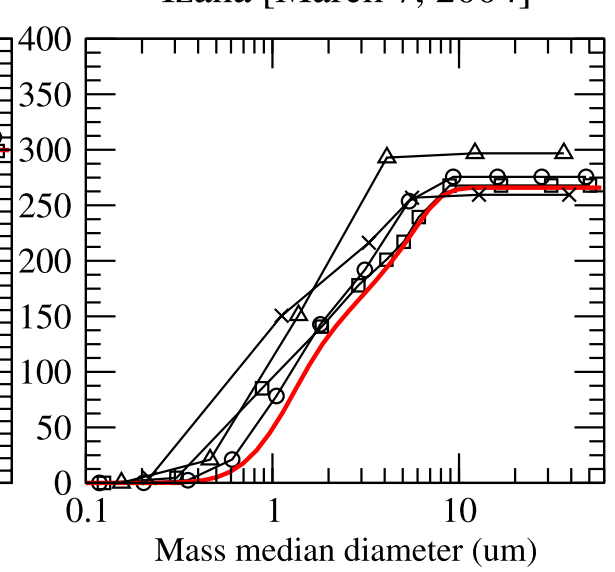

Figure 11. Cumulative dust concentrations as a function of the particle diameter for the five configurations and over three sites: Niamey, Capo Verde, and Izana. The data sets correspond to 6 March 2004, 00:00.

of the contribution of the larger particles to the total dust mass concentrations. In the vicinity of the source regions, the mass size distribution is characterized by a dominant size mode located between 1 and $20 \mu \mathrm{m}$ in diameter. The mass size distribution moves progressively to be dominated by the particles located around 1-2 $\mu \mathrm{m}$ in diameter (as simulated at Izana). When looking at the size distribution simulated for the two size bins schemes in relation with Figure 7, we observe that the main difference is that the $\log 12$ size bins scheme overestimates the concentrations in the size range $2-10 \mu \mathrm{m}$ (in which most of the transported mass is located). This is clearly due to an underestimation of the dry deposition velocity computed for this specific size range when using the $\log 12$ size bins scheme.

\section{Conclusion}

[45] The dust particle mass size distribution is a key parameter for an accurate modeling of their concentration fields over Africa and the northern Atlantic and to assess properly their biogeochemical and radiative impacts. In this paper, we have compared the dry deposition computation when using size bins schemes defined either from the "classical" isolog approach or from that recently proposed by Forêt et al. [2006] which prescribes the size bins according to the gradient of the dry deposition velocity. For a one-and-a-half-month period, simulations performed with the CHIMERE-DUST model over a large domain allow to estimate the dust concentrations by including emissions, transport, and deposition. For two different numbers of bins (6 and 12) in the size distribution, the two bins schemes are compared in terms of absolute and relative differences of the concentrations. This comparison is achieved using a reference case computed by using 40 size bins.

[46] We first conclude that the approach proposed by Forêt et al. [2006] leads to simulated concentrations more accurate than those obtained by using the isolog size bins scheme, this improvement being significant since the errors on dust concentrations are reduced by up to a factor of 2 . Obviously, the more that the size bins number is large, the more accurate are the concentrations fields. We also conclude that 6 bins are not sufficient to simulate precise dust concentrations fields, even when using the approach proposed by Forêt et al. [2006].

[47] However, the isogradient method requires to prescribe a mean friction velocity $u *$ to compute the dry deposition velocity function used to define the size bins. This constraint can generate errors if the selected friction velocity is not representative of the mean conditions 
encountered during the simulation. We thus recommend to use the friction velocity most frequently calculated over the domain of interest to define these size bins. Our tests suggest that a value of $u *=0.35 \mathrm{~m} / \mathrm{s}$ could be well adapted to simulate dust transport over the North Atlantic Ocean. For other studies, such as those dealing with dust modeling at global scale, we suggest to retain the friction velocity value most frequently observed with the model itself and over the domain of interest: This approach is thus relatively dependent on this parameter, but we showed that, in every cases, the error is reduced compared to the usual logarithmic distribution.

[48] Acknowledgments. The authors acknowledge Robert VAUTARD (LMD/IPSL) for the NCEP/AVN database and the MM5 model setup used in this paper

\section{References}

Alfaro, S. C., and L. Gomes (2001), Modeling mineral aerosol production by wind erosion: Emission intensities and aerosol size distribution in source areas, J. Geophys. Res., 106, 18,075-18,084.

Alpert, P., P. Kishcha, A. Shtivelman, S. O. Krichak, and J. H. Joseph (2004), Vertical distribution of Saharan dust based on 2.5-year model predictions, Atmos. Res., 70, 109-130.

Bessagnet, B., A. Hodzic, R. Vautard, M. Beekmann, S. Cheinet, C. Honoré, C. Liousse, and L. Rouil (2004), Aerosol modeling with chimere: Preliminary evaluation at the continental scale, Atmos. Environ., 38, 28032817.

Cakmur, R. V., R. L. Miller, and O. Torres (2004), Incorporating the effect of small-scale circulations upon dust emission in an atmospheric general circulation model, J. Geophys. Res., 109, D07201, doi:10.1029/ 2003JD004067.

Dudhia, J. (1993), A nonhydrostatic version of the Penn state/NCAR mesoscale model: Validation tests and simulation of an Atlantic cyclone and cold front, Mon. Weather Rev., 121, 1493-1513.

Forêt, G., G. Bergametti, F. Dulac, and L. Menut (2006), An optimized particle size bin scheme for modeling mineral dust aerosols, J. Geophys. Res., 111, D17310, doi:10.1029/2005JD006797.

Ginoux, P., J. M. Prospero, O. Torres, and M. Chin (2004), Long-term simulation of global dust distribution with the GOCART model: Correlation with North Atlantic oscillation, Environ. Model. Softw., 19, 113128.

Gong, S., et al. (2003), Canadian Aerosol Module: A size-segregated simulation of atmospheric aerosol processes for climate and air quality models, 1. Module development, J. Geophys. Res., 108(D1), 4007, doi:10.1029/2001JD002002.

Grini, A., and C. S. Zender (2004), Roles of saltation, sandblasting, and wind speed variability on mineral dust aerosol size distribution during the Puerto Rican Dust Experiment (PRIDE), J. Geophys. Res., 109, D07202, doi:10.1029/2003JD004233.

Han, Z., H. Ueda, K. Matsuda, R. Zhang, K. Arao, Y. Kanai, and H. Hasome (2004), Model study on particle size segregation and deposition during Asian dust events in March 2002, J. Geophys. Res., 109, D19205, doi:10.1029/2004JD004920.
Holben, B., et al. (2001), An emerging ground-based aerosol climatology: Aerosol optical depth from AERONET, J. Geophys. Res., 106, 12,06712,097 .

Jickells, T. D., et al. (2005), Global iron connections: Between desert dust, ocean biogeochemistry and climate, Science, 308, 67-71.

Kishcha, P., F. Barnaba, G. P. Gobbi, P. Alpert, A. Shtivelman, S. O. Krichak, and J. H. Joseph (2005), Vertical distribution of Saharan dust over Rome (Italy): Comparison between 3-year model predictions and lidar soundings, J. Geophys. Res., 110, D06208, doi:10.1029/ 2004JD005480.

Loosmore, G., and R. Cederwall (2004), Precipitation scavenging of atmospheric aerosols for emergency response applications: Testing an updated model with new real-time data, Atmos. Environ., 38, 993-1003.

Luo, C., N. Mahowald, and C. Jones (2002), Temporal variability of dust mobilization and concentration in source regions, J. Geophys. Res., 109(D20), 2020, doi:10.1029/2004JD004861.

Marticorena, B., and G. Bergametti (1995), Modeling the atmospheric dust cycle: 1 Design of a soil derived dust production scheme, J. Geophys. Res., 100, 16,415-16,430.

Menut, L. (2003), Adjoint modelling for atmospheric pollution processes sensitivity at regional scale during the ESQUIF IOP2, J. Geophys. Res., 108(D17), 8562, doi:10.1029/2002JD002549.

Menut, L., C. Schmechtig, and B. Marticorena (2005), Sensitivity of the sandblasting fluxes calculations to the soil size distribution accuracy, J. Atmos. Oceanic Technol., 22(12), 1875-1884.

Sandu, A., G. Liao, G. Carmichael, D. Henze, and J. Seinfeld (2005), Inverse modeling of aerosol dynamics using adjoints: Theoretical and numerical considerations, Aerosols Sci. Technol., 39, 677-694.

Schulz, M., Y. J. Balkanski, W. Guelle, and F. Dulac (1998), Role of aerosol size distribution and source location in a three-dimensional simulation of a Saharan dust episode tested against satellite-derived optical thickness, J. Geophys. Res., 103, 10,579-10,592.

Seinfeld, J. H., and S. N. Pandis (1998), Atmospheric Chemistry and Physics, John Wiley, Hoboken, N. J.

Sokolik, I., D. M. Winker, G. Bergametti, D. A. Gillette, G. Carmichael, Y. Kaufman, L. Gomes, L. Schuetz, and J. E. Penner (2001), Outstanding problems in quantifying the radiative impact of mineral dust, J. Geophys. Res., 106, 18,015-18,028.

Uno, I., et al. (2003), Regional chemical weather forecasting system CFORS: Model descriptions and analysis of surface observations at Japanese island stations during the ACE-Asia experiment, J. Geophys. Res., 108(D23), 8668, doi:10.1029/2002JD002845.

Van Leer, B. (1979), Towards the ultimate conservative difference scheme. V A second order sequel to Godunov's method, J. Comput. Phys., 32, $101-136$.

Vautard, R., M. Beekmann, J. Roux, and D. Gombert (2001), Validation of a hybrid forecasting system for the ozone concentrations over the Paris area, Atmos. Environ., 35, 2449-2461.

Venkatram, A., and J. Pleim (1999), The electrical analogy does not apply to modeling dry deposition of particles, Atmos. Environ., 33, 3075-3076. von Salzen, K. (2006), Piecewise log-normal approximation of size distributions for aerosol modelling, Atmos. Chem. Phys., 6, 1351-1372.

Zhang, L., S. Gong, J. Padro, and L. Barrie (2001), A size-segregated particle dry deposition scheme for an atmospheric aerosol module, Atmos. Environ., 35, 549-560.

G. Bergametti and G. Forêt, Laboratoire Inter-Universitaire des Systèmes Atmosphériques, Universités Paris7-Paris 12-CNRS, Créteil, France.

L. Menut, Laboratoire de Météorologie Dynamique, Institut PierreSimon Laplace, Ecole Polytechnique, Palaiseau, France. (menut@lmd. polytechnique.fr) 